\title{
Intelectuales en la prensa: polémica, antagonismo, ¿y polifonía?
} (Argentina, 2019)

\section{Intellectuals in the press: controversy, antagonism... and polyphony? (Argentina, 2019)}

ARTÍCULO

\author{
Magdalena Biota \\ Universidad Nacional de Quilmes, Argentina. Contacto: magdalena.biota@gmail.com
}

Recibido: agosto de 2020

Aceptado: octubre de 2020

\section{Resumen}

Sobre la base de una selección de notas de prensa publicadas en las ediciones digitales de Clarín, La Nación, Infobae, La Prensa y Perfil, este artículo se propone analizar algunos rasgos de las intervenciones de los intelectuales en la prensa en el contexto de una polémica ocurrida en Argentina entre septiembre y noviembre de 2019. La polémica, que surge en respuesta a las declaraciones del sociólogo e investigador Horacio González en una entrevista para un medio contra-hegemónico, pone en tensión la representación social de algunos acontecimientos de la historia reciente del país, y en particular, la conceptualización de la guerrilla en los '70. Los discursos que circularon con motivo de esa polémica evidencian ciertas estrategias textuales recurrentes que los actores sociales despliegan para (des)legitimar acciones e interpretaciones, y promover, perpetuar, negociar y discutir los sentidos a partir de los cuales se intenta una organización pública de la sociedad. Una de estas estrategias consiste en el recorte, borramiento y descontextualización del punto de vista. Como se intentará demostrar, la eficacia de esta estrategia reside en la capacidad de volver ilegítimos los argumentos, planteos e ideas del adversario, al extremo de anular o inhibir la réplica.

Palabras clave: Estrategias discursivas, argumentación, prensa, intelectuales, estudio de caso.

\footnotetext{
Abstract

Based on a selection of press releases published in the digital editions of Clarín, La Nación, Infobae, La Prensa and Perfil, this paper aims to analyze some features of the interventions of intellectuals in the press in the context of a controversy occurred in Argentina between
} 
September and November 2019. The controversy, which arises in response to the statements of the sociologist and researcher Horacio González in an interview for a counterhegemonic journal, challenges the social representation of some events in the recent history of the country, and in particular, the conceptualization of the guerilla in the 70s. The discourses that circulated on the occasion of this controversy show certain recurring textual strategies that social actors deploy to (de)legitimize actions and interpretations, and promote, perpetuate, negotiate and discuss the meanings from which a public organization of society is attempted. One of these strategies consists of clipping, erasing and decontextualizing the point of view. As this paper shall attempt to demonstrate, the effectiveness of this strategy lies in the ability to render the adversary's arguments, approaches and ideas illegitimate, to the point of nullifying or inhibiting any answer.

Keywords: Discourse strategies, argumentation, newspapers, intellectuals, case study.

\section{Introducción ${ }^{1}$}

Las intervenciones de los intelectuales pueden asumir distintos tipos de formas (incluyendo las más tradicionales, como discursos, disertaciones, artículos científicos, ensayos, libros, charlas, o las que surgen con las nuevas tecnologías, como tweets o blogs). Estas intervenciones llevan adscritas cualidades que en cierto modo las describen y que al mismo tiempo denotan un posicionamiento por parte del sujeto emisor. Sin problematizar, por ahora, en el posicionamiento implícito que pudiera resultar del uso de cada forma y cada plataforma en la que ésta circula (no es lo mismo la publicación en una revista científica, que las actas de un congreso, que una columna en un diario, que un tweet), podemos observar que al intervenir en la esfera pública los intelectuales asumen alguno o varios rasgos de los siguientes tipos de posicionamientos. El intelectual crítico, por ejemplo, se posiciona a sí mismo como un sujeto capaz de construir una representación de la realidad a partir de mostrar "la verdad y revelar el engaño" (Chomsky, 1969, p. 22). Por su parte, el intelectual comprometido, en los términos de Sartre, se asume "responsable del desenlace de cualquier acontecimiento de su época" (Pulleiro, 2013, p. 5). El intelectual revolucionario, forjado en la conciencia de los años setenta (Sondereguer, 2008), constituye la profundización y el pasaje del compromiso a la acción directa. Acaso Rodolfo Walsh en Argentina sea la figura que encarna esta categoría de manera más acabada: "el intelectual que encontró el atajo que llevaba de la palabra a la acción" (Pavón, 2012, p. 48). Frente a esta radicalización, el tecnócrata o intelectual especialista es aquel que presenta su trabajo en la academia o en

\footnotetext{
${ }^{1}$ Este trabajo forma parte de mi proyecto de tesis sobre cartas abiertas e intervenciones de los intelectuales en la esfera pública (Argentina, 2015-2019) en el marco del Doctorado en Ciencias Sociales y Humanas de la Universidad Nacional de Quilmes (UNQ), Argentina, dirigida por la Dra. Gabriela García Cedro.
} 
la burocracia estatal como "no política", pretendidamente exenta de ideología e interés. De manera similar, el intelectual no partidario se reserva para sí un espacio de intervención que, según su autoconstrucción, se aparta de cualquier categoría social vinculada con tareas organizativas.

Para Gramsci, cada nueva clase crea junto a ella y forma en su desarrollo progresivo grupos de intelectuales que son en general especializaciones de aspectos parciales de la actividad primitiva del tipo social nuevo que la nueva clase ha dado a luz (Gramsci, 2000, p. 10). Con la profundización de la hegemonía massmediática surge el intelectual mediático o "todólogo" un tipo de pensador que, ocupando generalmente posiciones subalternas en el campo intelectual, se adapta a todas las condiciones y asume todas las preguntas, aunque ello vaya en contra de la posibilidad de elaborar una interpretación valiosa de procesos sociales cada vez más complejos (Bourdieu, 1997, citado por Pulleiro, 2013, p. 11).

Se podrían enumerar otros arquetipos de intelectuales que atraviesan el arco nacional y latinoamericano, con cruces y matices históricos y coyunturales (nacionalistas vs. liberales, academicistas vs. antiacademicistas, elitistas oligarcas vs. populistas; de derecha vs. de izquierda; progresistas vs. conservadores; católicos vs. anticatólicos; científicos vs. antipositivistas, etc.), sin embargo estas categorías no pueden pensarse como compartimentos estancos. En la tradición abundan los ejemplos de intelectuales que fueron adhiriendo a distintas categorías a lo largo de su trayectoria, por ejemplo, el escritor argentino Leopoldo Lugones (Pavón, 2012, p. 24). Del mismo modo, estos arquetipos tampoco pueden pensarse como clases monolíticas y ahistóricas. Sintetizan un conjunto de rasgos característicos de cada momento en el que emergen y se resignifican.

Las interacciones de los intelectuales en la prensa pueden observarse a la luz de la teoría del posicionamiento para analizar las proyecciones que éstas suscitan como intervenciones públicas, teniendo en cuenta la situación delicada y dual de una clase social que se diferencia en ciertos aspectos de los grupos profesionales asalariados (en especial en cuanto a exposición, mecanismos de legitimación y prestigio social), pero cuyo espacio de inserción es netamente similar al de las profesiones liberales (Viñas, 1996). Esta posición pública denota una jerarquía y una distinción, y constituye un gesto de autoridad. Como figuras legitimadas para juzgar la situación sociopolítica del país por la acumulación colectiva de prestigio y respeto, representan una suerte de élite, que al mismo tiempo se manifiesta a favor de la igualdad de las voces en una democracia participativa. Esta paradoja del intelectual público y las tensiones asociadas a su rol social desde Dreyfus hasta el presente fueron discutidas por Baert y Booth en el artículo "Tensions within the public intellectual: political interventions from Dreyfus to the new social media" (Baert y Booth, 2012).

Estrechamente ligada a los orígenes del concepto moderno de intelectual e instrumento político público por excelencia, la prensa constituye un espacio para la 
construcción, masificación y canonización de la producción intelectual, pero sobre todo para legitimar acciones e interpretaciones que contribuyen a forjar modos de organizar públicamente las sociedades, y en este sentido simboliza la misma tensión entre igualdad y jerarquía. La eficacia de estas intervenciones textuales se apoya en el estatus y la autoridad de una pequeña élite antes que en la validez y veracidad de la progresión argumentativa.

Sobre la base de una selección de notas de prensa publicadas en las ediciones digitales de Clarín, La Nación, Infobae, La Prensa y Perfil, este artículo se propone analizar algunos rasgos de las intervenciones de los intelectuales en la prensa en el contexto de una polémica ocurrida en Argentina entre septiembre y noviembre de 2019. La polémica, que surge en respuesta a las declaraciones del sociólogo, investigador y ex Director de la Biblioteca Nacional Argentina Horacio González en una entrevista (Palacio, 2019) para la Agencia Paco Urondo (APU) $)^{2}$, pone en tensión la representación social de algunos acontecimientos de la historia reciente del país, y en particular, la conceptualización de la guerrilla en los '70. Los discursos que circularon con motivo de esta polémica evidencian ciertas estrategias textuales recurrentes que los actores sociales despliegan para (des)legitimar acciones e interpretaciones, y promover, perpetuar, negociar y discutir los sentidos a partir de los cuales se intenta una organización pública de la sociedad. Una de estas estrategias consiste en el recorte, borramiento y descontextualización del punto de vista, como un efecto de los textos con fines argumentativos. Como se intentará demostrar, la eficacia de esta estrategia reside en la capacidad de volver ilegítimos los argumentos, planteos e ideas del adversario, al extremo de, desde el punto de vista pragmático, anular o inhibir la réplica.

\section{Metodología}

Para la elaboración de este artículo, se abordó el estudio de la selección textual por medio de métodos cuantitativos y cualitativos, tanto para su registro y sistematización, como para su interpretación (Wodak y Meyer, 2003). Si bien se apeló a las dos estrategias, el propósito central estuvo orientado a construir un modelo de observación fundamentalmente cualitativo que permitió arriesgar una serie de hipótesis acerca de las motivaciones, valoraciones y percepciones que los intelectuales proyectaron a través del material verbal con que intervinieron en la esfera pública.

${ }^{2}$ La Agencia Paco Urondo (APU) es un portal de noticias de Argentina creado en 2005. Organizado como un "colectivo de comunicación", según las bases de la economía cooperativa, las licencias Creative Commons y el software libre, se autoproclama como un gestor de periodismo militante. Los temas que aborda incluyen la política, la cultura, la violencia institucional y los derechos humanos, y el género. Lleva su nombre en homenaje a Francisco Urondo, un escritor, periodista, poeta y militante político secuestrado en Mendoza junto con su esposa e hija de ocho meses, y asesinado a golpes en esa ciudad por las fuerzas de seguridad de la última dictadura cívico-militar (Argentina, 1976-1983). 
En primer lugar, se construyó un marco teórico basado en la actualización de la bibliografía específica, con el objetivo de discutir y debatir perspectivas epistemológicas adecuadas para la interpretación y organización de la selección. Apelando al análisis crítico del discurso, se revisó y sistematizó la serie textual teniendo en cuenta los distintos niveles significativos de la enunciación: el situacional (los interlocutores, el lugar de producción y circulación, el tiempo y todos los datos relativos a la enunciación), el semántico (los contenidos conceptuales), el funcional (los efectos perseguidos) y el formal (las selecciones de distintos recursos del sistema lingüístico, la distribución retórica de los contenidos). En este modelo, los aspectos formales fueron considerados en sí mismos significativos en tanto producen efectos de sentido; a la vez, el análisis formal permitió extraer indicadores que permiten asignar valor a los demás niveles.

Desde el punto de vista situacional, se analizaron los sujetos discursivos (locutor y destinatarios, así como contradestinatarios) y se observaron las estrategias utilizadas en los distintos medios de comunicación a través de los cuales se distribuyeron los textos que conforman la selección. Respecto de los contenidos, se identificó la información y el punto de vista a fin de caracterizar las estrategias discursivas. En cuanto al nivel funcional, se analizaron los efectos perseguidos. La selección incluye distintos géneros del registro periodístico, tanto informativos como argumentativos: noticias, columnas de opinión, editoriales, comentarios, testimonios y cartas abiertas.

El análisis se basó en los siguientes artículos, enumeradas por orden cronológico:

1. Polémicas declaraciones de Horacio González: habló de una "valoración positiva" de la guerrilla de los 70 (2019, 22 de septiembre).

2. Horacio González pidió una "valoración positiva de la guerrilla de los años 70 " (2019, 22 de septiembre).

3. Horacio González, de Carta Abierta: "CFK no puede ser una mera vicepresidenta" (2019, 23 de septiembre).

4. Pichetto, ante una vuelta del kirchnerismo al poder: "Quien tenga un departamento de más, va tener que entregarlo a la revolución" (2019, 23 de septiembre).

5. Miguel Ángel Pichetto: "Quien tenga un departamento de más, va tener que entregarlo a la revolución" (2019, 23 de septiembre).

6. El Gobierno cuestionó la "valoración positiva" de Horacio González sobre la guerrilla de los años 70 (2019, 23 de septiembre).

7. Leuco, Alfredo (2019, 23 de septiembre).

8. El presidente de la Corte lo cruzó a Horacio González por sus dichos sobre la guerrilla de los 70 (2019, 24 de septiembre).

9. Laborda, Fernando (2019, 24 de septiembre).

10. Quienes nada han aprendido $(2019,25$ de septiembre).

11. Un grupo de intelectuales cuestionó a Horacio González por sus dichos sobre la guerrilla (2019, 26 de septiembre).

12. Beatriz Sarlo: "Horacio González tiene amnesia por la edad" (2019, 27 de septiembre).

13. Lucha armada en los ' 70 : un debate sin cerrar que vuelve una y otra vez $(2019,28$ de septiembre).

14. Luna, Jovina (2019, 2 de octubre). 
15. Gallardo, Juan Luis (2019, 11 de octubre).

Por sus características formales, estrategias discursivas y aspectos contextuales, las intervenciones de los intelectuales suponen un posicionamiento polémico con respecto a un adversario explícito o implícito, rasgo fundamental de lo político según Verón, quien considera que "[l]a enunciación política parece inseparable de la construcción de un adversario" (Verón, 1985). Partimos de un concepto de práctica social discursiva y de texto desarrollado por Foucault (1969), Chartier $(1994,1996)$ y del Análisis Crítico del Discurso (Fairclough y Wodak, 1997; van Dijk, 1999), de la Teoría de las Representaciones Sociales (Moscovici, 1976; Jeanneret, 1994; Chartier, 1996; Jodelet, 2000, Cortassa, 2012) y de un modelo de análisis proveniente de la Lingüística del Texto de orientación comunicativa (Ciapuscio, 2003 y 2010), según las sistematizaciones teóricas formuladas por Peralta:

Entendemos por práctica social discursiva una acción verbal -eventualmente combinada con acciones llevadas a cabo a través de otros sistemas simbólicos-, articulable con prácticas sociales no discursivas; situada en el tiempo y el espacio, y en el interior de algún campo socio-discursivo, considerando -en medidas variablesotros campos con los que aquél se vincule; que persigue la producción de efectos relativos a alguna clase de intereses; realizada según reglas dependientes de una red compleja de representaciones sociales de distinto nivel (Peralta, 2016, p. 40).

Aún en los casos en que por convenciones de género la función predominante no estaba vinculada con la argumentación, la presentación de los contenidos semánticos y la selección léxica se orientó a convencer al interlocutor o auditorio y al argumentatario, si lo hubiera, y a desprestigiar al adversario ideológico.

\section{La producción textual en el contexto político}

Los momentos históricos se construyen a partir de las prácticas y las representaciones que los actores producen en relación con esas prácticas; al mismo tiempo ellos mismos son construidos a través de las prácticas y las representaciones de cada época y cada sociedad. Desde esta perspectiva, este artículo se propone un abordaje semiótico social, esto es: "[...] un examen de la operación de la "gramática" de cada figura del discurso, sus leyes sintácticas o requerimientos, sus configuraciones imaginarias, sus redes metafóricas, y también por supuesto lo que no articula en el nivel del enunciado: sus silencios" (Irigaray, 1977, p. 75).

El itinerario trazado por las sucesivas intervenciones de los intelectuales permite construir - casi siempre de manera clara - los contextos cambiantes en la situación comunicativa. La selección textual que vamos a analizar se publicó en los diarios más leídos en Argentina entre el 22 de septiembre y el 11 de octubre de 2019 en un momento de gran incertidumbre política en el país, y la noticia fue replicada en otros medios locales de menor 
circulación. Los discursos se escribieron y circularon durante el último tramo del proceso de campaña política en Argentina, que se inauguró con las elecciones primarias abiertas obligatorias (PASO). Las PASO dieron una provisoria y frágil victoria al partido opositor Frente de Todos. Confirmada por las elecciones definitivas del 27 de octubre, esta victoria pondría fin al mandato presidencial macrista.

Cuando el 22 de septiembre de 2019, la Agencia Paco Urondo (APU) publicó la entrevista a Horacio González, aún no se habían celebrado las elecciones presidenciales que consagrarían en primera vuelta con el 48,24\% - de acuerdo con el escrutinio definitivo- a la dupla Fernández-Fernández como presidente y vicepresidenta. En las dinámicas discursivas predominaban la argumentación basada en la cita sesgada y la circulación de información parcial, lo cual se utilizaba con ánimos de persuadir a un público masivo, por lo general irreflexivo, desinformado o indeciso. En este momento social de incertidumbre y especulación preelectoral, el testimonio de González repercutió con la rúbrica de subjetividad cartista, aludiendo al colectivo Espacio Carta Abierta $^{3}$, del que formaba parte. Si bien esta vez las ideas no estaban plasmadas en una carta abierta, sus declaraciones en la entrevista fueron rápidamente adscriptas al colectivo, replicadas por medios masivos y contestadas por diversos actores sociales (intelectuales, periodistas, el Presidente de la Corte Suprema de Justicia, el Presidente del Senado y candidato a la vicepresidencia, familiares de víctimas, entre otros).

Las notas criticaban especialmente las alusiones de Horacio González a la lucha armada en los 70 , por un lado, y a sus apreciaciones sobre lo que el intelectual esperaba que fuera el rol de Cristina Fernández como vicepresidenta, por el otro. En los apartados que siguen, se observará el esquema comunicacional, la representación del discurso ajeno y la selección léxica a fin de identificar algunas de las estrategias puestas en escena en los textos. La hipótesis que orientó la observación estuvo vinculada con la percepción de que en todas estas estrategias predominó la intención de construir una retórica del recorte para desarticular los argumentos del adversario. Si bien esto puede pensarse como una característica del discurso político periodístico, este debate muestra la particularidad de introducir la figura intelectual y utilizarla como estrategia para construir prestigio y legitimidad respecto de las conclusiones del debate. Sin embargo, al observar las estrategias con las que los argumentos son construidos y refutados, podemos comprobar que los discursos carecen de la densidad dialéctica que podría esperarse de un ejercicio intelectual más riguroso. En síntesis, el debate tal como quedó formulado colocó a Horacio González en el lugar del autoritario y a los defensores del autoritarismo (o al menos de un discurso autoritario, según el análisis del discurso) como intelectuales.

\footnotetext{
${ }^{3}$ Para referencias sobre el colectivo Carta Abierta, cf.: Pavón, 2012 y 2013; Retamozo, 2012; Pulleiro, 2013.
} 


\section{Esquema comunicacional: el dominio de los medios}

En este apartado, se analizará el esquema comunicacional, es decir, la información referida a los emisores y receptores, el mensaje, y el canal, incluyendo lo que puede inferirse acerca de la línea editorial de los medios observados.

La selección de textos está conformada por quince artículos periodísticos que forman una unidad comunicativa, en tanto refieren a los dichos de González y dialogan entre sí. Todos fueron publicados en diarios digitales de gran alcance, dirigidos a un público masivo. Un grupo de estos medios se dirige a un interlocutor relativamente más culto (La Nación, Clarín y Perfil), mientras que el otro grupo se orienta a un interlocutor más popular (Infobae y La Prensa). Esto puede inferirse a partir de ciertas características textuales vinculadas con las estrategias apelativas, las referencias intertextuales y los géneros discursivos.

En los textos de la prensa culta predominan estrategias orientadas a persuadir a través de conceptos o relaciones de ideas, mientras que los de la prensa popular tienden a recurrir mayormente a la emotividad. El primer grupo recurre además con más frecuencia a las referencias intertextuales y a la cita (directa e indirecta), mientras que el segundo grupo lo hace en menor grado y siempre integrando los discursos aludidos dentro del propio texto (sin enlaces externos). La distribución por géneros discursivos es la siguiente: tres noticias, cuatro columnas de opinión, una carta abierta, cuatro testimonios (uno de los cuales, el del candidato a Vicepresidente por Cambiemos, está publicado verbatim en dos medios, Clarín y Perfil) y un híbrido (que mezcla rasgos de palabras del editor con recursos estilísticos de la parábola o el dicho).

Los géneros utilizados permiten construir un espacio de legitimación de la voz. Las estrategias varían según los medios, siguiendo las convenciones de género. En las noticias, en general sin firma o firmadas bajo las iniciales del nombre, la voz se legitima por medio de los rasgos formales del discurso periodístico: los hechos se presentan por su relevancia en la escena política nacional. En las columnas de opinión, importan los nombres de quienes opinan y su voz está legitimada en función de una jerarquía social, vinculada con la trayectoria y un capital intelectual acumulado (cf.: Selección Textual: Nota de Prensa \# 13). En la carta abierta, el enunciado está legitimado a partir de adhesiones de intelectuales (en realidad, periodistas y políticos, cf.: Selección Textual: Nota de Prensa \# 11). En los testimonios publicados en La Nación, Perfil y Clarín, la palabra está legitimada a partir de la autoridad del sujeto de la enunciación, su estatus en el espacio social: quienes enuncian son funcionarios públicos del Poder Ejecutivo, del Poder Judicial, del Poder Legislativo, dirigentes políticos electos o en candidatura. En el testimonio publicado en Infobae, la legitimidad se construye a partir de la experiencia personal, íntima: quien enuncia se autoproclama como familiar de una víctima. 
En este marco enunciativo, es notable la transgresión del texto que postulamos como un híbrido. Mezclando rasgos de las palabras del editor y la parábola o el dicho, este texto titulado "Quienes nada han aprendido" (cf.: Selección Textual: Nota de Prensa \# 10) construye un espacio de contraofensiva o descargo. Si fuera posible adscribirle un acto de habla, sería el de mensaje de advertencia. El ejercicio discursivo que reproduce se basa en la estrategia del sentido común: es tan contundente que no puede ser contestado. ¿Dónde queda colocado el receptor en esta trama comunicativa?

Como fue demostrado en los estudios sobre la comunicación periodística, la recepción de la prensa está sesgada ideológicamente. La ideología social de los lectores condiciona la manera de acercarse al discurso mediático y la forma de procesarlo. En términos generales, cada lector se acerca a aquellos medios acordes con su visión de la realidad. Sin embargo, en la selección se observa que todos los medios construyen una misma visión, repetida con mínimas variaciones en cada artículo. Esta tendencia a consolidar un discurso único que se repite y refuerza, contradice la presunción de elección de los lectores. En otras palabras, cuando una persona decide leer los diarios para informarse y cree que elige, accede a una narrativa que le dicta indiscriminadamente una visión única de la realidad.

Este mundo alterno de la comunicación periodística dedicado a influenciar las representaciones sociales de los lectores, generar adhesiones y asegurar la estigmatización de los adversarios, constituye un medio de difusión ideológica contundente. La prensa va armando el basamento discursivo de la sociedad a partir de representaciones, conceptos y un universo de asociaciones. En las democracias, los medios de prensa son actores estratégicos que operan sobre el espacio de las comunicaciones entre ciudadanía y política.

\section{Representación del discurso ajeno: sospechosa pluralidad}

En este apartado, se analizará la representación del discurso ajeno en los distintos artículos de la selección. Particularmente se identificarán las estrategias que determinan el espacio intertextual y el uso de las marcas de condescendencia.

Una de las características más llamativas de esta polémica es la dinámica de las intervenciones. Habitualmente una polémica se construye a partir de las intervenciones de participantes antagónicos que se van contestando a lo largo del tiempo, polarizando el espacio discursivo. En este caso, la polémica se lee de manera unilateral. No hay ida y vuelta. Las palabras del adversario aparecen citadas en los textos de los oponentes. Todos los enunciatarios en esta polémica antagonizan con esa cita. Del otro lado, no hay respuestas. ¿De qué manera ingresa la cita en el espacio de los textos?

En el caso de las noticias casi idénticas difundidas por Clarín y La Nación el mismo día que se publicara la entrevista a Horacio González en APU, las palabras del sociólogo aparecen entrecomilladas y la fuente citada, sin el hipervínculo a la entrevista. Estas notas 
que por convenciones de género tienen un propósito informativo, emplean estrategias discursivas que generan un efecto argumentativo, en especial a partir de la adjetivación ("polémicas declaraciones") y las marcas de condescendencia ("valoración positiva de la guerrilla). Respecto de este último caso, el empleo de la cita textual cumple el propósito de poner al adversario en evidencia bajo sus mismos términos, estableciendo de esta manera un tipo de uso irónico de las palabras ajenas.

En las notas subsiguientes, cuando Clarín y La Nación remiten a la entrevista citada, incluyen en el texto propio un enlace a la noticia previamente publicada por estos medios. La fuente (viz.: la entrevista) queda reducida a la selección argumental de los oponentes. Los contenidos se replican en varias páginas web y medios de menor alcance, produciendo un efecto de réplica en diversidad de fuentes, pero todos los sitios reproducen el recorte editorial de los grandes medios prácticamente en las mismas palabras.

Este juego de voces semejante a un coro entonando al unísono produce un efecto amplificado que replica la cita sesgada y recortada, privándola del sentido con el que fue dicha, borrando la intención y su contexto de producción. Este uso de la dimensión polifónica contribuye a desarticular el punto de vista del oponente y quitarle toda fuerza argumentativa. Cuando la polémica avance y otros actores "dialoguen” con González, lo harán refiriéndose a la cita, no a la fuente. Esto también se aplica a los intelectuales, supuestamente advertidos respectos de los mecanismos de control discursivo.

\section{Selección léxica: de la cita textual a la interpretación monopólica}

Los discursos pueden pensarse como el campo simbólico en el que los actores sociales buscan legitimar sus acciones e interpretaciones para promover, perpetuar, negociar y discutir los sentidos que contribuyen a forjar modos de organizar públicamente las sociedades. En la selección textual se observa una tematización de la guerrilla y una semantización de esta última como terrorismo. En este apartado observaremos algunas operaciones y estrategias que sirven para reforzar la construcción ideológica por medio del uso de redes léxico semánticas.

Las selecciones léxicas y la construcción de campos semánticos, guiada por fines comunicativos, juegan un rol decisivo en la génesis, producción y construcción de ciertas condiciones sociales. Estas construcciones semánticas, en la forma de redes léxico semánticas, persiguen objetivos estratégicos en el discurso político: legitimar, deslegitimar, oponer, polarizar la opinión pública y condicionar la representación de la realidad.

A partir de la selección léxica, los textos analizados fueron unánimes al caracterizar a González de autoritario, a los movimientos sociales de terroristas y a la ciudadanía de víctimas de una guerra interna entre los comunistas y los que ("gracias a Dios", sic) salvaron al país de las ruinas, logrando aniquilar al enemigo. Esta alta adhesión a una narrativa, y su 
reproducción acrítica en los grandes medios, genera una situación de precariedad que no contribuye a la comprensión de los procesos históricos. La estigmatización de ciertos actores sociales a través de las operaciones ideológicas de la prensa genera un campo discursivo que es necesario observar y resistir con prácticas críticas.

\section{Discusión}

Un diario dirigido por un excremento como usted lleva camino de ser fraccionado en cuadrilongos y colgado en la pared de un retrete.

\section{Carta de José Ingenieros a Bartolomé Mitre}

En ese momento social de incertidumbre y especulación preelectoral, el testimonio de González repercutió con la rúbrica de subjetividad cartista. Si bien esta vez las ideas no estaban plasmadas en una carta abierta, las declaraciones en la entrevista fueron rápidamente adscriptas al colectivo, replicadas por medios masivos y contestadas por diversos actores sociales y políticos (intelectuales, periodistas, el Presidente de la Corte Suprema de Justicia, el Presidente del Senado y candidato opositor a la vicepresidencia, familiares de víctimas, entre otros). Las notas criticaban especialmente las alusiones de Horacio González a la lucha armada en los '70, por un lado, y a sus apreciaciones sobre lo que esperaba que fuera el rol de Cristina Fernández como vicepresidenta, por el otro. Lo primero que se puede observar en la serie es el proceso de resemantización del término lucha armada, que aparece como sinónimo de guerrilla y terrorismo. Incluso guerrilla criminal y asesinos surgen como equivalentes funcionales. También es llamativo que distintos medios titulan de manera idéntica o utilizan una misma frase copiada de manera textual. $\mathrm{Si}$ avanzamos en la lectura, las dinámicas discursivas se basan predominantemente en la desacreditación a partir de estigmas sociales (la edad, por ejemplo, en el título de Beatriz Sarlo), la argumentación basada en la cita sesgada y la circulación de información parcial, lo cual podríamos deducir que fue utilizado para persuadir a un público masivo y no necesariamente informado que se esperaba podía revertir el resultado de las PASO.

Vastísima es la tradición polémica entre intelectuales en Argentina, tal como puede advertirse a partir del epígrafe que abre este apartado. En la tradición polemista argentina no se escatima en vituperios y agresivas desacreditaciones que marcan la divisoria de aguas entre los grupos que luchan por las significaciones: tener la razón, atesorar el poder de la palabra y la prerrogativa de hacer callar. El mismo día que APU publicó la entrevista, La Nación publicó el primero de una serie de artículos periodísticos. Esa misma semana, publicó la carta abierta de un grupo de intelectuales alarmados por los dichos de González. La estrategia utilizada por el diario fue dual. Por un lado, hizo hipertexto autorreferencial cuando la cita es a la entrevista a González: en vez de remitir la fuente original, enlazó a la 
nota de opinión escrita por el mismo diario, con los sesgos y las inquietudes del caso. Por el otro, publicó íntegra la réplica del grupo de intelectuales. Esto resulta en una descontextualización de las declaraciones de González, y un recorte, un borramiento, del punto de vista.

La eficacia de la estrategia de recorte, borramiento y descontextualización del punto de vista, como un efecto de menor jerarquía en el contexto de un enunciado cuyos fines son notablemente argumentativos, reside en la capacidad de volver ilegítimos los argumentos, planteos e ideas del adversario, al extremo de anular o inhibir la réplica. La misma estrategia es la que utilizó Clarín.

Perfil, haciendo buen uso del hipertexto, redirige a la fuente de la APU. Sin embargo, construye el discurso a partir de la alarma y en clave de termómetro para dirimir cuál será la correlación de fuerzas al interior de la alianza del Frente de Todos. Simplifica y especula.

En las columnas de opinión, las prácticas discursivas no son menos superficiales. Sergio Bufano, escritor, periodista y columnista de opinión, además de mandar a González a leer Controversia, se pregunta sobre la delgada línea de lo individual y lo colectivo/partidario en las declaraciones: “¿Los dichos de Horacio González son representativos de lo que ocurrirá si eventualmente Alberto Fernández y Cristina asumen la conducción del país? Prefiero imaginar que es una manifestación individual. Recordemos, por favor." Esta inquietud por la posible colectivización de los dichos abre interrogantes respecto del rol de un sector intelectual que establece un tipo de enunciación basada en la alarma, promoviendo la activación de nudos traumáticos del pasado y dictando una serie de tópicos que deberían ser tabú.

La alusión a la revista Controversia para el examen de la realidad argentina, que se editó en México D. F. entre octubre de 1979 y agosto de 1981, también funciona como un conjuro: una fórmula mágica que pretende invocar todo lo dicho y clausurar en el mismo acto cualquier revisión, parcial o no, de aquello que está escrito sobre el tema. Promovida por un grupo de exiliados argentinos en México, cuyos miembros habían sido parte, o habían apoyado en el país, el proyecto liderado por la organización Montoneros y la Tendencia Revolucionaria del Peronismo, la revista abordó temas vinculados con la lucha armada, el exilio argentino, las teorías marxistas, el peronismo, los derechos humanos, la dictadura. Su relato sobre la historia reciente de la Argentina se volvió canónico y fue retomado por los trabajos académicos publicados desde mediados de los años ochenta, consagrando una línea interpretativa que en términos generales se continúa en el presente. Según esta interpretación, el proyecto político revolucionario había sufrido una derrota irreversible, por lo cual sus presupuestos teóricos y políticos debían ser revisados. Una de las certezas puestas en duda fue la de la viabilidad de la lucha armada para producir el pasaje del peronismo al socialismo, y la de la legitimidad del ejercicio de la violencia por parte de las organizaciones armadas. Esta visión dominante, impulsada desde esos años, es lo que 
González invita a revisar para poder construir sentidos que ofrezcan nuevas claves en la lectura de la realidad política de aquellos años y a partir de allí interpretar el contexto actual. La apelación a la cita de Controversia es en este contexto obturador del ejercicio intelectual que González propone en la entrevista de APU y por eso mismo es una grave falta de rigor crítico y honestidad entre pares, que no debería ser naturalizada ni pasar inadvertida.

Beatriz Sarlo, periodista, escritora y ensayista, decidió construir su columna a partir de la retórica del titeo. El significado de titeo viene de titear, una palabra de origen onomatopéyico que alude al cantar de la perdiz llamando a los pollos y que en sentido figurado, se usa para referir a las palabras de humillación pública que en general una patota dirige a alguien que queda vulnerado. Sostuvo que la edad es sinónimo de amnesia y repitió "no-lo-sé" como un mantra. Con tono de preocupación alarmada, denunció la existencia de un "federalismo argentino y monstruoso", apelando a la difamación no sólo del intelectual sino de todo una tradición política que intenta pensar alternativas a la visión porteña y unitaria del país. Por todo esto, consideramos que su aporte en este caso carece de la densidad a la que nos acostumbró en los años en que leía la Revista Martín Fierro.

Juan Luis Gallardo, abogado, profesor en ciencias políticas de la Universidad Católica Argentina (UCA) y columnista en distintos medios de prensa, en un solo párrafo, agradeció a Dios (sic), felicitó el accionar de la Dictadura y concluyó categórico: "las Fuerzas Armadas y de Seguridad se encargaron de evitar el éxito guerrillero, acertaran o no en el método empleado para obtener el triunfo. Y a despecho de las nostalgias de González". Si observamos la forma de argumentar planteada en la cita, podemos inferir una inversión de los valores de las proposiciones. "Los métodos empleados para obtener el triunfo" aparece como una entidad relativizada, cuando justamente es a causa de esos métodos que en el plano jurídico las acciones de las Fuerzas Armadas y de Seguridad fueron caratuladas como crímenes de lesa humanidad. Claramente, en el plano simbólico, esta inversión es una estrategia para desafiar las representaciones sociales sobre los acontecimientos y exonerar de culpa a los responsables.

Ninguno de los medios de prensa que se hizo eco de la entrevista profundizó sobre las ideas planteadas por González. Los referentes del campo intelectual en vez de dialogar (en el sentido bajtiano del término, es decir, en vez de tomar el enunciado y reelaborarlo), respondieron a una caracterización inexacta de lo dicho, que no estaba en la fuente sino en las notas de prensa, y desestimaron los argumentos calificándolos de "zurdismo de los setenta montoneros" (Casullo, 2008). Sin embargo, si observamos las palabras de González y el contexto en que estableció la necesidad de restituir una voz a las ideas de la historia, podemos advertir que la intención de traer la experiencia al presente del discurso no implicó una invitación a repetir miméticamente las acciones del pasado. Se propuso en cambio como un llamado al ejercicio crítico, para desafiar lecturas de época a la luz del drama histórico, con todas sus contradicciones: 
Hay que reescribir la historia argentina pero no en esa especie de neoliberalismo inspirado en las academias norteamericanas de los estudios culturales, donde hay una multiplicidad graciosa y finita. Sino que tiene que ser una historia dura y dramática, que incorpore una valoración te diría positiva de la guerrilla de los años 70 y que escape un poco de los estudios sociales que hoy la ven como una elección desviada, peligrosa e inaceptable (Palacio, 2019).

Las palabras de González invitan a resistir las categorías y lecturas impuestas desde una visión parcial y acotada ("finita") de los hechos del pasado reciente, los cuales según su perspectiva tienen matices no finitos que han sido inexplorados por el tabú impuesto desde las visiones consagradas con las que se intentó sepultar las tensiones de la década.

$\mathrm{Si}$ entre las fuentes de la historia se encuentran los documentos periodísticos, es necesario advertir que un análisis del pasado reciente no es posible sin revisar críticamente los discursos sobre los cuales esas fuentes se construyen. En este sentido, es vital observar el desplazamiento desde los cuerpos hacia las ideas. Si en los setenta, la desaparición forzada de personas se estableció como una modalidad sistemática de represión política, en este tiempo prevalece la desaparición y tergiversación sistemática de aquellos argumentos que perturban el orden de lo constituido. Walsh fue emboscado por una patota de la Escuela de Mecánica de la Armada que lo hizo desaparecer un día después de publicar su "Carta abierta a la Junta Militar", el 25 de marzo de 1977: es un hecho irrefutable. El estudio del rol de los medios en la construcción de la guerrilla armada así como en la preparación de los golpes blandos en Latinoamérica podría abordarse a partir de las formas en que esos hechos fueron concebidos, enunciados y legitimados discursivamente. La violencia extendida en los medios de mayor alcance persigue fines represivos y naturalizarla es un error grave.

\section{Palabras finales}

En este artículo se analizó una selección de notas de prensa publicadas en las ediciones digitales de Clarín, La Nación, Infobae, La Prensa y Perfil, con el objeto de caracterizar las dinámicas discursivas y observar los rasgos de las intervenciones de los intelectuales en la prensa en el contexto de la polémica sobre la guerrilla de los 70 , ocurrida en Argentina entre septiembre y noviembre de 2019. La polémica, que surge en respuesta a las declaraciones del sociólogo e investigador Horacio González en una entrevista pone en tensión la representación social de algunos acontecimientos de la historia reciente del país.

Los discursos que circularon con motivo de esa polémica evidenciaron una serie de estrategias textuales que los actores sociales utilizaron para (des)legitimar acciones e interpretaciones, y promover, perpetuar, negociar y discutir los sentidos a partir de los cuales se intenta una organización pública de la sociedad. Principalmente el uso del recorte, 
borramiento y descontextualización del punto de vista fue eficaz para volver ilegítimos los argumentos, planteos e ideas del adversario, al extremo de anular o inhibir la réplica. Esperamos que este artículo haya servido de aporte al campo de la historia reciente y de la memoria sobre la violencia, a partir de la reflexión y las herramientas propuestas por el análisis crítico del discurso. Para profundizar este tipo de análisis, podría ser interesante relevar las repercusiones del debate en las redes sociales, cuyo análisis quedó fuera de la selección textual y de los propósitos de este artículo.

En el campo intelectual, la construcción del sujeto de la enunciación se establece con el propósito de ejercer el oficio de las ideas, que objetivado como práctica colectiva, inaugura un espacio público que invita a la reflexión y a la participación del poder. Gremialistas, periodistas, sindicalistas, actores y actrices, académicos, comunicadores, dirigentes, con sus enfoques y perspectivas, contribuyen a reflexionar sobre el presente e intervienen en los debates, proponiendo agendas, resistiendo embates, impulsando gestas. Estos espacios públicos tensan las lógicas de lo individual, y permiten disputar el sentido de lo político que involucra a otras y otros significativos. Las formas políticas de la palabra, como modos de acción verificables en el plano de lo material, penetran los espacios discursivos y dotan a los textos de capacidad transformadora.

Hay una serie de problemas que pueden atisbarse en la construcción de los discursos masivos que circulan en el espacio público. Las estrategias que los intelectuales ponen en práctica al intervenir implican un posicionamiento. Caracterizar estas estrategias desde el punto de vista del análisis crítico del discurso puede considerarse un aporte sustantivo para promover la pluralidad de voces en el espacio de las comunicaciones entre ciudadanía y política en las democracias, considerando que los medios de prensa tienden a monopolizar el privilegio de la palabra.

\section{Notas periodísticas analizadas}

Polémicas declaraciones de Horacio González: habló de una "valoración positiva" de la guerrilla de los 70 (2019, 22 de septiembre). Clarín. Recuperado de: https://www.clarin.com/politica/polemicas-declaraciones-horacio-gonzalez-hablovaloracion-positiva-guerrilla-70 0 ssxl5PK .html

Horacio González pidió una "valoración positiva de la guerrilla de los años 70" (2019, 22 de septiembre). La Nación. Recuperado de: https://www.lanacion.com.ar/politica/horaciogonzalez-cristina-no-puede-ser-mera-nid2290263

Horacio González, de Carta Abierta: "CFK no puede ser una mera vicepresidenta" (2019, 23 de septiembre). Perfil. Recuperado de: https://www.perfil.com/noticias/politica/horaciogonzalez-de-carta-abierta-cfk-no-puede-ser-una-mera-vicepresidenta.phtml 
Pichetto, ante una vuelta del kirchnerismo al poder: "Quien tenga un departamento de más, va tener que entregarlo a la revolución" (2019, 23 de septiembre). Clarín. Recuperado de: https://www.clarin.com/politica/pichetto-vuelta-kirchnerismo-poder-departamento-va-tenerentregar-revolucion- 0 XMynla7w.html

Miguel Ángel Pichetto: "Quien tenga un departamento de más, va tener que entregarlo a la revolución" (2019, 23 de septiembre). Perfil. Recuperado de: https://www.perfil.com/noticias/politica/miguel-angel-pichetto-dijo-horacio-gonzalez-escristina-kirchner-es-incontinente-verbal.phtml

El Gobierno cuestionó la "valoración positiva" de Horacio González sobre la guerrilla de los años 70 (2019, 23 de septiembre). Clarín. Recuperado de: https://www.clarin.com/politica/gobierno-cuestiono-valoracion-positiva-horacio-gonzalezguerrilla-anos-70 0 V9riSZg9.html

Leuco, Alfredo (2019, 23 de septiembre). Guerrilla criminal. Radio Mitre (Grupo Clarín). Recuperado de: https://radiomitre.cienradios.com/guerrilla-criminal-por-alfredo-leuco/

El presidente de la Corte lo cruzó a Horacio González por sus dichos sobre la guerrilla de los $70 \quad(2019,24$ de septiembre). Clarín. Recuperado de: https://www.clarin.com/politica/presidente-corte-cruzo-horacio-gonzalez-dichos-guerrilla$\underline{70 \quad 0 \text { v3Kj1cyo.html }}$

Laborda, Fernando (2019, 24 de septiembre). La injustificable reivindicación de los guerrilleros. La Nación. Recuperado de: https://www.lanacion.com.ar/politica/lainjustificable-reivindicacion-de-los-guerrilleros-nid2290672

Quienes nada han aprendido (2019, 25 de septiembre). La Nación. Recuperado de: https://www.lanacion.com.ar/editoriales/quienes-nada-han-aprendido-nid2291003

Un grupo de intelectuales cuestionó a Horacio González por sus dichos sobre la guerrilla (2019, 26 de septiembre). La Nación. Recuperado de: https://www.lanacion.com.ar/politica/un-grupo-intelectuales-cuestiono-horacio-gonzalez$\underline{\text { sus-nid2291793 }}$

Beatriz Sarlo: "Horacio González tiene amnesia por la edad" (2019, 27 de septiembre). Perfil. Recuperado de: https://www.perfil.com/noticias/politica/beatriz-sarlo-dijo-horacio-gonzaleztiene-amnesia-por-laedad.phtml?fb comment id=2500666433354856 2501262609961905

Lucha armada en los '70: un debate sin cerrar que vuelve una y otra vez (2019, 28 de septiembre). Perfil. Recuperado de: https://www.perfil.com/noticias/elobservador/luchaarmada-en-los-70-un-debate-sin-cerrar-que-vuelve-una-y-otra-vez.phtml

Luna, Jovina (2019, 2 de octubre). Horacio González pide reivindicar a los asesinos de mi hermano. Infobae., Recuperado de: https://www.infobae.com/opinion/2019/10/02/horaciogonzalez-pide-reivindicar-a-los-asesinos-de-mi-hermano/

Gallardo, Juan Luis (2019, 11 de octubre). Reivindicación terrorista. La Prensa. Recuperado de: http://www.laprensa.com.ar/481773-Reivindicacion-terrorista.note.aspx 


\section{Referencias bibliográficas}

Baert, P. y Booth, J. (2012). Tensions within the public intellectual: political interventions from Dreyfus to the new social media, en International Journal of Politics, Culture, and Society, 25(4), 111-126.

Casullo, N. (2008, 13 de julio). La carta robada. Página/12. Recuperado de: https://www.pagina12.com.ar/diario/elpais/1-107762-2008-07-13.html

Chartier, R. (1996). La historia hoy en día: dudas, desafíos, propuestas. En Olábarri, I. y Capistegui, F. M. La "nueva" historia cultural, la influencia del postestructuralismo y el auge de la interdisciplinariedad (pp. 19-33). Madrid: Editorial Complutense.

Chomsky, N. (1969). American power and the new mandarins. New York: Vintage BooksRandom House.

Ciapuscio, G.; Adelstein, A. y Gallardo, S. (2010). El texto especializado: propuesta teórica y prácticas de capacitación académica y profesional. En Parodi, G. (Ed.). Alfabetización académica y profesional en el Siglo XXI: leer y escribir desde las disciplinas (pp. 317-345). Santiago de Chile: Planeta.

Cortassa, C. (2012). La ciencia ante el público. Dimensiones epistémicos y culturales de la comprensión pública de la ciencia. Buenos Aires: Eudeba.

Foucault, M. (1969). La arqueología del saber. México: Siglo XXI.

González, H. (2016). Tomar las armas. Buenos Aires: Colihue.

Gramsci, A. (2000). Los intelectuales y la organización de la cultura. Buenos Aires: Nueva Visión.

Irigaray, L. (1985 [1977]). This sex which is not one. Ithaca, New York: Cornell University Press.

Jeanneret, Y. (1994). Ecrire la Science. Formes et enjeux de la vulgarisation. París: PUF. Jodelet, D. (2000). Presentación. Representaciones sociales: contribución a un saber sociocultural sin fronteras. En: Jodelet, D. y Guerrero Tapia, A. Develando la cultura. Estudios en representaciones sociales. México: UNAM-Facultad de Psicología.

Moscovici, S. (1976). La psychanalyse, son image et son public. París: Presse Universitaire de France.

Palacio, Ezequiel (2019, 22 de septiembre), Horacio González: "La cultura es la estructura secreta de todo lo que se hace, incluso en materia de economía". Agencia Paco Urondo. Recuperado de: http://www.agenciapacourondo.com.ar/cultura/horacio-gonzalez.

Pavón, H. (2012). Intelectuales y la política en Argentina. El combate por las ideas 19832012. Buenos Aires: Debate.

Pavón, H. (2013). Argentina: el regreso de los intelectuales públicos, en Nueva Sociedad 245, 149-162. 
Peralta, D. A. J. (2016), La ciencia y «La Razón»: la divulgación e información sobre ciencia en un diario de circulación masiva en perspectiva histórica (1917-1930). Buenos Aires: Universidad de Buenos Aires-Facultad de Filosofía y Letras. Disponible en: http://repositorio.filo.uba.ar/jspui/bitstream/filodigital/6105/1/uba ffyl t 2016 48770.pdf.

Pulleiro, A. (2013). El papel de los intelectuales en la Argentina reciente: una aproximación a la experiencia de 'Carta Abierta'. Buenos Aires: CONICET.

Retamozo, M. (2012). Intelectuales, kirchnerismo y política: una aproximación a los colectivos de intelectuales en Argentina. La Plata: Universidad Nacional de La PlataFacultad Humanidades y Ciencias de la Educación.

Sondereguer, M. (2008). Revista Crisis (1973-1976): antología. Bernal: UNQ.

Van Dijk, T. (1999). Ideología. Una aproximación multidisciplinaria. Barcelona: Gedisa.

Verón, E. (1987). La palabra adversativa. Observaciones sobre la enunciación política. En Verón, E. (et al.). El discurso político: lenguajes y acontecimientos. Buenos Aires: Hachette. Viñas, D. (1996). Literatura argentina y política. Buenos Aires: Sudamericana.

Wodak, R. y Meyer, M. C. (2003). Métodos de análisis crítico del discurso. Barcelona: Gedisa. 